\title{
Effects of Quinupramine on the Central Monoamine Uptake Systems and Involvement of Pharmacokinetics in Its Pharmacological Activities
}

\author{
Hirohiko SAKAMOTO, Nobuharu YOKOYAMA, Takashi NISHIMOTO, \\ Kazuyuki MURAI*, Hiroshi TATSUMI*, Shigekatsu KOHNO \\ and Katsuya OHATA \\ Department of Pharmacology, Kyoto Pharmaceutical University, \\ Yamashina, Kyoto 607. Japan \\ *Research Laboratories, Nippon Shoji Kaisha, Ltd., \\ Ibaraki, Osaka 567, Japan \\ Accepted June 29, 1987
}

\begin{abstract}
The effects of a new tricyclic antidepressant drug. quinupramine, on the monoamine uptake of rat brain homogenate preparations were studied in comparison with imipramine. Pharmacokinetic studies on quinupramine and imipramine in plasma and brain were also performed in rats after a single oral administration. Quinupramine had few effects on the noradrenaline and serotonin uptake both in in vitro and ex vivo models. After the administration of $\left[{ }^{3} \mathrm{H}\right]$ quinupramine, the unchanged drug was estimated as $60-75 \%$ of the total radioactivity in the cerebral cortex. Imipramine and desipramine preferentially inhibited the uptake of serotonin and noradrenaline, respectively, in vitro. After the administration, imipramine showed a marked inhibitory effect on noradrenaline uptake. A considerable amount of desipramine but not imipramine could be detected in the brain and plasma after the adminisration of $\left[{ }^{3} \mathrm{H}\right]$ imipramine. These results demonstrate that 1 ) the antidepressant activity of quinupramine cannot be attributed to inhibition of monoamine uptake, 2) unchanged quinupramine penetrates into the CNS and affects some of the processes of neurotransmission and 3) the pharmacological activities of imipramine. when administered orally, may be attributed to desipramine, the metabolite formed.
\end{abstract}

It is generally believed that antidepressant drugs affect the availability of neurotransmitters in the symapses interfering with some of the mechanisms of neurotransmission particularly those of the release and reuptake of various neurotransmitters at the presynaptic level (1). These neuropharmacological studies of antidepressant drugs have not taken into account the pharmacokinetic factors of these drugs, for example their concentration in the brain, the site of action of the drugs. Imipramine inhibits the uptake of serotonin to a greater extent than that of noradrenaline. However, its metabolite desipramine preferentially inhibits noradrenaline uptake $(1,2)$. In general, tricyclic antidepressant drugs with a tertiary-amine structure have pharmacologically active metabolites containing a secondary-amine (3).

Quinupramine, (5-1 -azabicyclo[2,2,2]oct3-yl) - 10,11-dihydro-4H-dibenz [b.f] azepine. is a new antidepressant drug with a quinuclidine group as a moiety of the molecule. which confers a great rigidity to the iminodibenzyl molecule, resulting in a great stability against enzymatic processes (4) and an increased binding affinity to biological receptors $(5,6)$. In clinical trials, quinupramine was equipotent to amitriptyline at onetenth the dose (7). In the present studies. the relationship between some neurochemical effects and brain concentrations of quinupramine was investigated and compared 
with those of imipramine.

\section{Materials and Methods}

Radioactive materials: $\left[\mathrm{Imino}-{ }^{3} \mathrm{H}\right]$ quinupramine (specific activity of $10.2 \mathrm{Ci} / \mathrm{mmol}$ ) was prepared by Amersham International (Buckinghamshire, England) by catalytic reduction of LM-29024, 5-(3-quinuclidinyl)$5 H$-dibenz $[\mathrm{b}, f]$ azepine (Groupe Pharmuka, Gennevilliers, France) with tritium gas. The tritiated compound was purified by thin-layer chromatography on silica gel. $\left[1 \operatorname{mino}^{-3} \mathrm{H}\right]$ imipramine $(20 \mathrm{Ci} / \mathrm{mmol}), 5$-hydroxy $\left[\mathrm{G}-{ }^{3} \mathrm{H}\right]$ tryptamine creatinine sulfate $(72.8 \mathrm{Ci} / \mathrm{mmol})$, $\left[7,8-{ }^{3} \mathrm{H}\right]$ dopamine $(40 \mathrm{Ci} / \mathrm{mmol})$ and $/-$ $\left[7,8{ }^{3} \mathrm{H}\right]$ noradrenaline $(35.4 \mathrm{Ci} / \mathrm{mmol})$ were purchased from Amersham International.

Chemicals: Unlabeled materials were obtained from the following sources: quinupramine (LM-208, Groupe Pharmuka, and Nippon Shoji Kaisha, Ltd., Osaka, Japan). indalpine (LM-5008. Groupe Pharmuka). imipramine hydrochloride and nialamide (Sigma Chemical Co., St. Louis, MO, U.S.A.) and desipramine hydrochloride (Ciba-Geigy Japan, Ltd.. Takarazuka, Japan). Other chemicals of reagent grade were obtained commercially.

Uptake of monoamines: The uptake of monoamines were determined by the methods of Baumann and Maitre (8) with slight modification.

Adult male Wistar rats (Shizuoka Laboratory Animal Center, Hamamatsu, Japan). weighing 150 to $200 \mathrm{~g}$. were used. After decapitation, the brains were removed, and specific regions, the forebrain for serotonin, the striatum for dopamine, and the hypothalamus for noradrenaline, were dissected over ice immediately before the experiments, as described by Glowinski and Iversen (9). The brains were homogenized in 10 volumes of ice-cold $0.32 \mathrm{M}$ sucrose with a glass homogenizer fitted with a teflon pestle. The homogenate was centrifuged twice at $1.000 \times \mathrm{g}$ for $10 \mathrm{~min}$, and the combined supernatant was used for the following experiment. Aliquots of $0.1 \mathrm{ml}$ of the supernatant were diluted with $0.7 \mathrm{ml}$ of modified Krebs-Henseleit bicarbonate solution (10) containing $200 \mathrm{mg}$ ascorbic acid, $25 \mathrm{mg}$ EDTA and $3.725 \mathrm{mg}$ nialamide per one liter.
To the resultant solutions, test compounds were added at different concentrations. $\left[{ }^{3} \mathrm{H}\right]$ Noradrenaline. $\left[{ }^{3} \mathrm{H}\right]$ dopamine or $\left[{ }^{3} \mathrm{H}\right]$ serotonin was added to yield final concentrations of $10 \mathrm{nM}, 10 \mathrm{nM}$ and $1.7 \mathrm{nM}$, respectively, in a total volume of $1 \mathrm{ml}$. The incubation tubes were filled with an $\mathrm{O}_{2}$ (95\%) $-\mathrm{CO}_{2}(5 \%)$ gas mixture, stoppered and incubated at $37^{\circ} \mathrm{C}$ for 30 (noradrenaline and dopamine) or $15 \mathrm{~min}$ (serotonin). Incubation was terminated by cooling to $0^{\circ} \mathrm{C}$. The labeled tissue preparations were collected on Millipore filters (type HA, 0.45 um; Millipore Corp., Bedford, MA, U.S.A.). Radioactivities on the dried filters were determined in a liquid scintillation spectrometer (Mark 1II. Searle Analytic, Des Plaines, IL, U.S.A.) in $8 \mathrm{ml}$ of Biofluor (NEN Research Products, Boston, MA, U.S.A.). For the determination of non-specific uptake, the incubation was performed at $0^{\circ} \mathrm{C}$ without the addition of test compounds.

To estimate the activity of monoamine uptake inhibition ex vivo, experiments were carried out in the drug treated rats. The rats were sacrificed 2 hr after the drug treatment, and brains were removed. The determinations of the uptake of monoamines were made under the conditions described above.

Pharmacokinetic study: Male Wistar rats, weighing 150 to $200 \mathrm{~g}$. were given a single dose of $10 \mathrm{mg} / \mathrm{kg}$ of $\left[{ }^{3} \mathrm{H}\right]$ quinupramine or $\left[{ }^{3} \mathrm{H}\right]$ imipramine hydrochloride as a $0.5 \%$ suspension of sodium carboxymethyl cellulose. The animals were sacrificed at various time intervals after treatment. Blood was collected from the abdominal aorta with a heparinized syringe and centrifuged at $1.500 \times \mathrm{g}$ for $10 \mathrm{~min}$ to obtain plasma samples. Brains were rapidly removed, washed with cold saline and dissected as described above.

Plasma samples of $0.1 \mathrm{ml}$ were pipeted into $8 \mathrm{ml}$ of Aquasol-2 (NEN Research Products), and the total radioactivity was measured in a liquid scintillation spectrometer.

For the study on the metabolites of quinupramine and imipramine, the methods of Nishimoto et al. (11) and Negy and Treiber (12), respectively, were used with some modifications. Briefly, $1.5 \mathrm{ml}$ of plasma in a glass tube was added to extractant. 
methanol $(6 \mathrm{ml})$ for quinupramine or $\mathrm{n}$ heptane $(6 \mathrm{ml})$ containing $3 \%$ amylalcohol for imipramine. The tube was shaken and then centrifuged at $1,500 \times \mathrm{g}$ for $10 \mathrm{~min}$. The organic phase was transferred to another glass tube, and the extraction procedure was repeated three times. The combined organic phases were evaporated under a stream of nitrogen at $45^{\circ} \mathrm{C}$. The residue was dissolved in $100 ~ \mu l$ methanol. The metabolites were separated and estimated by thin layer chromatography by using a solvent system of dichloroethane - ethyl acetate - - ethanol - acetic acid-distilled water $(30: 28: 8.5: 8.5: 5$ $\mathrm{v} / \mathrm{v}$ ) quinupramine (11) or that of chloroform - diethylether - methanol — ammonium hydroxide $(80: 15: 20: 0.2 \mathrm{~V} / \mathrm{v})$ for imipramine (12).

Tissues were homogenized with 1.5 to $3 \mathrm{ml}$ of distilled water in a glass pestle tissue homogenizer. The metabolites in the tissues were determined by the procedure described above. The recoveries from plasma or tissues varied from 80 to $96 \%$.

\section{Results}

Monoamine uptake inhibition: Table 1 shows the concentrations of the drugs required to inhibit the uptake of monoamines by $50 \%$ (IC50 values determined by loglogit analysis from concentration-response curves).

The uptake of $\left[{ }^{3} \mathrm{H}\right]$ serotonin and $\left[{ }^{3} \mathrm{H}\right]$ noradrenaline was inhibited in a concentration-dependent manner by quinupramine with an IC50 of $2.04 \times 10^{-6}$ and $5.05 \times 10^{-6} \mathrm{M}$, respectively. However, the activity of quinupramine in the serotonin uptake inhibition was 11 times less potent than imipramine $\left(\mathrm{IC} 50=1.78 \times 10^{-7} \mathrm{M}\right)$. Quinupramine had much weaker activity (27 times) than desipramine $\left(I C 50=1.87 \times 10^{-7} \mathrm{M}\right)$ in the noradrenaline uptake inhibition. Thus, quinupramine had a weak activity in the monoamine uptake inhibition. Desipramine was the most potent inhibitor of the noradrenaline uptake, but was a weak inhibitor of the serotonin uptake. Indalpine was very potent in inhibiting the serotonin uptake, but was less potent in inhibiting the noradrenaline uptake. All the compounds tested were very weak inhibitors of the dopamine uptake.

Figure 1 shows the effects of the pretreatment of quinupramine or imipramine on the uptake of $\left[{ }^{3} \mathrm{H}\right]$ serotonin and $\left[{ }^{3} \mathrm{H}\right]$ noradrenaline to the brain in rats. In this ex vivo test model, the activities of quinupramine in inhibiting the serotonin and noradrenaline uptake were only marginal (about 30 and $50 \%$ inhibition, respectively, at $100 \mathrm{mg} / \mathrm{kg}$. p.o.). In a low dose of $10 \mathrm{mg} / \mathrm{kg}$. imipramine inhibited predominantly the noradrenaline uptake, and the serotonin uptake inhibition was negligible. In higher doses, imipramine affected the serotonin and noradrenaline uptake to the same degree.

Pharmacokinetic study: After a single oral administration of $\left[{ }^{3} \mathrm{H}\right]$ quinupramine, the peak of total radioactivity in the plasma and cerebral cortex was observed at $30 \mathrm{~min}$ and $1 \mathrm{hr}$, respectively. At $1 \mathrm{hr}$ after administration. the total radioactivity in the cerebral cortex was almost equal to that of the plasma. The rate of elimination of the total radioactivity from the cerebral cortex was similar to that from the plasma. The unchanged drug was estimated as $5-10 \%$ of the total radioactivity in the plasma and estimated as $60-75 \%$ in the cerebral cortex. The concentrations of unchanged drug in the cerebral cortex were

Table 1. In vitro inhibition of the uptake of tritiated amines into rat brain homogenate preparations

\begin{tabular}{lccc}
\hline Compound & Serotonin & Dopamine & Noradrenaline \\
Quinupramine & $2.040 \pm 155$ & $25,400 \pm 2.790$ & $5.050 \pm 890$ \\
Imipramine & $178 \pm 29$ & $20,900 \pm 2.600$ & $766 \pm 43$ \\
Desipramine & $2,010 \pm 138$ & $15,200 \pm 1,670$ & $187 \pm 31$ \\
Indalpine & $11 \pm 1$ & $15,500 \pm 340$ & $2,610 \pm 508$ \\
\hline
\end{tabular}

Homogenate preparations from rat forebrain ( $\left[{ }^{3} \mathrm{H}\right]$ serotonin, $1.7 \mathrm{nM}$ ), striatum ( $\left[{ }^{3} \mathrm{H}\right]$ dopamine, $10 \mathrm{nM}$ ) or hypothalamus ( $\left.{ }^{3} \mathrm{H}\right]$ noradrenaline, $10 \mathrm{nM}$ ) were incubated at $37^{\circ} \mathrm{C}$ for 15 (serotonin) or 30 (noradrenaline and dopamine) min. Each value represents the mean \pm S.E.M. (IC50 in nM) of at least 3 experiments in duplicate using $3-5$ drug concentrations. 


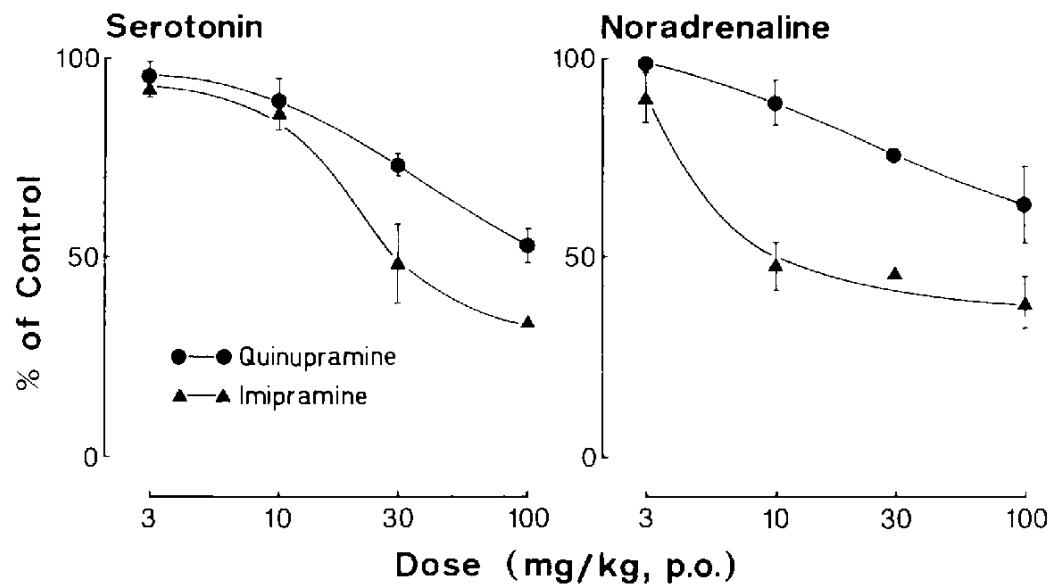

Fig. 1. Inhibitory effects of quinupramine and imipramine on the uptake of $\left[{ }^{3} \mathrm{H}\right]$ serotonin and $\left[{ }^{3} \mathrm{H}\right]$ noradrenaline into rat brain homogenate preparations. The drugs were pretreated $2 \mathrm{hr}$ before sacrifice. Each point represents the mean \pm S.E.M. of 3 animals.

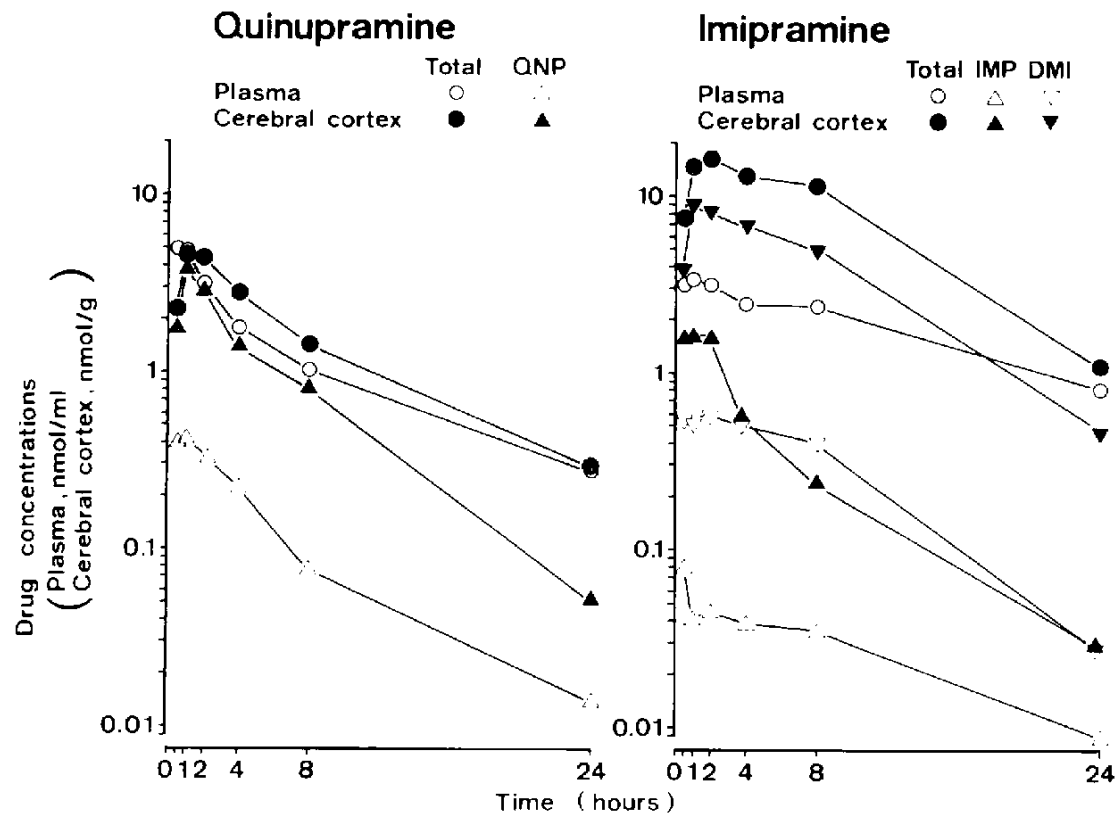

Fig. 2. Drug concentrations in plasma and cerebral cortex after a single oral administration of $\left[{ }^{3} \mathrm{H}\right]$ quinupramine or $\left[{ }^{3} \mathrm{H}\right]$ imipramine at a dose of $10 \mathrm{mg} / \mathrm{kg}$. Each point represents the mean value obtained from three rats. S.E.s did not exceed $20 \%$ of the mean values. Abbreviations for substances used are: QNP, quinupramine; IMI, imipramine: DMI, desipramine.

6-9 times higher than those in the plasma (Fig. 2).

After a single oral administration of $\left[{ }^{3} \mathrm{H}\right]$ imipramine, the peak of total radioactivities in the plasma and cerebral cortex was observed at 1 and $2 \mathrm{hr}$, respectively. The total radioactivity in the cerebral cortex was about 5 times higher that in the plasma. Only low concentrations of the unchanged drug could be detected in the cerebral cortex and 
Table 2. Distribution of total radioactivity in various regions of rat brain $2 \mathrm{hr}$ after a single oral administration of $\left[{ }^{3} \mathrm{H}\right]$ quinupramine or $\left[{ }^{3} \mathrm{H}\right]$ imipramine at a dose of $10 \mathrm{mg} / \mathrm{kg}$

\begin{tabular}{lcr}
\hline & \multicolumn{2}{c}{ Total radioactivity } \\
\cline { 2 - 3 } Tissues & Quinupramine & Imipramine \\
Plasma & $3.15 \pm 0.23$ & $3.45 \pm 0.10$ \\
Cortex & $4.46 \pm 0.32$ & $17.40 \pm 0.86$ \\
Cerebellum & $3.87 \pm 0.54$ & $14.78 \pm 0.65$ \\
Medulla Pons & $4.57 \pm 0.54$ & $16.24 \pm 0.69$ \\
Hippocampus & $5.89 \pm 0.87$ & $17.33 \pm 0.12$ \\
Striatum & $5.75 \pm 0.94$ & $19.77 \pm 5.34$ \\
Hypothalamus & $5.62 \pm 0.46$ & $15.51 \pm 0.38$ \\
Midbrain + Thalamus & $4.15 \pm 0.29$ & $15.46 \pm 0.29$ \\
\hline
\end{tabular}

Each value represents the mean \pm S.E. of data obtained from three rats. Tissue concentrations are expressed as the nmol equivalerit to tritium labeled material per $\mathrm{g}$ of tissue. Plasma levels are expressed as nmol equivalent $/ \mathrm{ml}$.

plasma: however, imipramine concentrations were about 10 times higher in the cerebral cortex than in the plasma. On the other hand, desipramine was estimated as $20 \%$ of the total radioactivity in the plasma and estimated as $60-70 \%$ of that in the cerebral cortex. The concentrations of desipramine in the plasma and cerebral cortex were about 10 times higher than those of imipramine (Fig. 2).

As shown in Table 2, marked differences of drug distribution in various brain regions were not observed for either of the drugs with the exception of the cerebellum, in which the radicactivities were slightly lower than any of the other regions. In all brain regions, the ratios of the unchanged drugs and respective metabolites to the total radioactivities were not significantly different from those of the cerebral cortex (data not shown).

\section{Discussion}

In general, typical tricyclic antidepressant drugs have a $\mathrm{N}$-dimethyl-aminoalkyl side chain in their molecule. However, quinupramine has a cyclic tertiary-amine, quinuclidine, in place of the side chain moiety. This difference may provide quinupramine with different pharmacological properties. That is, quinupramine was found to possess high affinities for serotonin $S_{2}$, muscarinic cholinergic and histamine $H_{1}$ receptors in rat brain $(5,6)$. Especially, the affinity for serotonin $\mathrm{S}_{2}$ receptors was higher than that of amitriptyline, imipramine, clomipramine and desipramine (6). By contrast, its affinity for imipramine binding sites was only one seventieth that of imipramine (5). Langer et al. (13) have suggested that high affinity $\left[{ }^{3} \mathrm{H}\right]$ imipramine binding might be associated with the mechanism of serotonin uptake in the brain, because the correlation between the potencies for the inhibition of $\left[{ }^{3} \mathrm{H}\right]-$ imipramine binding and those for inhibition of uptake of serotonin of various antidepressant drugs is highly significant. From this respect, we had presumed that quinupramine was a weak inhibitor for the neural uptake of serotonin. The present study showed directly the weak inhibitory activity of quinupramine in not only the central serotonin but also the central noradrenaline uptake.

The monoamines, serotonin and noradrenaline, have been considered to play an important role in depression. The catecholaminergic and serotonergic hypotheses of affective disorders relate the etiology to a deficiency of the monoamines at their respective central synapses. Both hypotheses may currently considered to be oversimplifications (1). There are various interactions between antidepressant drugs and monoamine functions that have been emphasized for their therapeutic action: (i) a blockade of monoamine uptake systems, (ii) an apparent antagonism on various pre- and postsynaptic receptors and (iii) a down-regulation of $\beta$-adrenergic and/or serotonin $S_{2}$ 
receptors (1). However, their contribution to psychotherapeutic research has been extremely profound. The uptake processes into the presynaptic neurones are considered to be a major route to inactivate monoamines at the neural synapses, and tricyclic antidepressant drugs are thought to act by virtue of their ability to block monoamine uptake. However quinupramine was found to be a weak inhibitor for monoamine uptake both in vitro and ex vivo. Thus the antidepressant activity quinupramine cannot be attributed to inhibition of monoamine uptake.

Indalpine, one of the 4-(3-indolyl-alkyl) piperidine derivatives, selectively inhibited the serotonin uptake, and this agrees with the findings by Le Fur et al. (14).

Imipramine inhibited the serotonin uptake in a concentration-dependent manner in an in vitro model. On the other hand, imipramine, when it was administered orally, inhibited the noradrenaline uptake at lower doses than those that were required for inhibition of the serotonin uptake.

Imipramine is rapidly absorbed from the gastrointestinal tract, and the peak plasma level of its total radioactivitiy was reached at $1 \mathrm{hr}$ after oral administration. However, only low concentrations of the unchanged drug could be detected in the plasma and cerebral cortex. On the other hand, very high concentrations of desipramine, one of the metabolites of imipramine, were detected. Several hydroxylated metabolites had been also reported in the blood and brain following oral administration of imipramine (15). These hydroxylated metabolites also have substantial pharmacological activities (16). However, brain concentrations of these hydroxylated metabolites are so low that the apparent pharmacological activities of orally administered imipramine may be attributed to the desipramine formed.

Unlike other tricvclic antidepressant drugs, quinupramine does not have a $N$ dimethyl-aminoalkyl side chain to be demethylated in the liver. The extensive appearance of total radioactivity in the plasma and brain after oral administration of $\left[{ }^{3} \mathrm{H}\right]$ quinupramine indicates its rapid absorption and distribution in rats, and the low plasma and high brain concentrations of the un- changed drug indicate that quinupramine has a greater affinity to the rat brain. The predominant route of biotransformation of quinupramine in rats is hydroxylation of azepine and the aromatic moiety of the molecule (12), and these metabolites have very weak pharmacological activities ( $M$. Hojo, personal communication). Thus, pharmacological activity after systemic quinupramine treatment may be attributed to the unchanged drug.

Quinupramine and imipramine pass the blood-brain barrier very rapidly, reaching high concentrations in various brain regions. Slightly high radioactivities were found in the hippocampus, striatum and hypothalamus after $\left[{ }^{3} \mathrm{H}\right]$ quinupramine or $\left[{ }^{3} \mathrm{H}\right]$ imipramine treatment. It is very interesting that antidepressant drugs distribute to the brain regions rich in $\beta$-adrenergic (17) or serotonin $S_{2}$ (18) receptors, and their activities may be related to the $\beta$-adrenergic and/or serotonin $S_{2}$ systems (1). That is, we can suggest that antidepressant drugs distribute to these brains areas, and reveal the pharmacological action via neurotransmitters and/or these receptors, which exist in these brain regions. Studies of neurotransmitter receptors have indicated that antidepressant drugs may mediate their clinical effects by down-regulating $\beta$ adrenergic and/or serotonin $S_{2}$ receptors. These observations have led to studies on the abnormalities of these receptors in depressed patients (1). On the other hand. depression is not a homogeneous illness (19). and different antidepressant drugs may be required for different subtypes of depression.

Antidepressant drug therapy requires a long term administration, so the drug accumulation to specific regions in the brain may cause adverse reactions, for example. extrapyramidal disorders. Therefore, further pharmacokinetic and clinical pharmacological studies are needed.

\section{References}

1 Sugrue, M.F.: Current concepts on the mechanisms of action of antidepressant drugs. Pharmacol. Ther. 13, 219-247 (1981)

2 Koe, B.K: Molecular geometry of inhibitors of the uptake of catecholamines and serotonin in synaptosomal preparations of rat brain. J. Phar- 
macol. Exp. Ther. 199, 649-661 (1976)

3 Scoggins, B.A., Maguire, K.P., Norman, T.R. and Burrows, G.D.: Measurement of tricyclic antidepressants. Part I; A review of methodology. Clin. Chem. 26, 5-17 (1980)

4 Bouquet, S., Lefebvre, M.A., Girault. J. and Fourtillan, J.B.: Étude pharmacocinétique de la quinupramine, en cross-over chez six subjets. Encéphale 8, 449-463 (1982)

5 Sakamoto, H., Yokoyama. N., Kohno, S. and Ohata, K.: Receptor binding profile of quinupramine, a new tricyclic antidepressant. Japan. J. Pharmacol. 36, 455-460 (1984)

6 Sakamoto, H., Yokoyama, N., Nishimoto, T., Murai, K., Tatsumi, H., Kohno, S. and Ohata, K.: Binding characteristics of $\left[{ }^{3} \mathrm{H}\right]$ quinupramine to rat brain membrane fractions. Japan. J. Pharmacol. 45, 27-36 (1987)

7 Neuman, N.: Quinupramine. Med. Actual. 16, 119-124 (1980)

8 Baumann, P.A. and Maître, L.: Blockade of presynaptic $\alpha$-receptors and of amine uptake in the rat brain by the antidepressant mianserine. Naunyn Schmiedebergs Arch. Pharmacol. 300, $31-37$ (1977)

9 Glowinski, J. and Iversen, L.L.: Regional studies of catecholamines in the rat brain-1: The disposition of $\left[{ }^{3} \mathrm{H}\right]$ norepinephrine, $\left[{ }^{3} \mathrm{H}\right]$ dopamine and $\left[{ }^{3} \mathrm{H}\right] \mathrm{DOPA}$ in various regions of the brain. J. Neurochem. 13,655-669 (1966)

10 Besson, M.J., Cheramy, A., Feltz, P. and Glowinski, J.: Release of newly synthesized dopamine from dopamine-containing terminals in the striatum of the rat. Proc. Natl. Acad. Sci. U.S.A. 62, 741-748 (1969)

11 Nishimoto, T., Yokoyama, N., Sakamoto, H., Murai, K., Tatsumi, H. and Ohata, K.: Metabolic fate of quinupramine (4); Metabolism of quinupramine in rats, lyakuhin Kenkyu (Abs. in English) (in press)

12 Negy, A. and Treiber, L.: Quantitative determination of imipramine and desipramine in human blood plasma by direct densitometry of thin-layer chromatograms. J. Pharm. Pharmacol. 25, 599-603 (1973)

13 Langer, S.Z., Moret, C., Raisman, R., Dubocovich, M.L. and Briley, M.: High-affinity $\left[{ }^{3} H\right]$ imipramine binding in rat hypothalamus; Association with uptake of serotonin but not of norepinephrine. Science 210, 1133-1135 (1980)

14 Le Fur, G., Kabouche, M. and Uzan, A.: On the regional and specific serotonin uptake inhibition by LM 5008. Life Sci. 23, 1959-1966 (1978)

15 Barkai, A.I., Suckow, R.F. and Cooper, T.B.: Imipramine and its metabolites; Relationship to cerebral catecholamines in rat in vivo. J. Pharmacol. Exp. Ther. 230, 330-335 (1984)

16 Javaid, J.I., Perel, J.M. and Davis, J.M. Inhibition of biogenic amines uptake by imipramine, desipramine, $20 \mathrm{H}$-imipramine and $20 \mathrm{H}$ desipramine in rat brain. Life Sci. 24, 21-28 (1979)

17 Bylund, D.B. and Snyder, S.H.: Beta adrenergic receptor binding in membrane preparations from mammalian brain. Mol. Pharmacol. 12, 568-580 (1976)

18 Leysen, J.E., Niemegeers, C.J.E., Van Nueten, J.M. and Laduron, P.M.: $\left[{ }^{3} \mathrm{H}\right]$ Ketanserin (R 41468 ), a selective ${ }^{3} H$-ligand for serotonin, receptor binding sites: Binding properties, brain distribution, and functional role. Mol. Pharmacol. 21, 301-314 (1982)

19 Maas, J.W.: Clinical and biochemical heterogeneity of depressive disorders. Ann. Intern. Med. $88,556-563$ (1987) 